\title{
Diallyl trisulfide induces apoptosis in human primary colorectal cancer cells
}

\author{
CHUN-SHU YU ${ }^{1}$, AN-CHENG HUANG ${ }^{2}$, KUANG-CHI LAI $^{3}$, YI-PING HUANG ${ }^{4}$, \\ MENG-WEI LIN ${ }^{5}$, JAI-SING YANG ${ }^{6}$ and JING-GUNG CHUNG ${ }^{5,7}$ \\ ${ }^{1}$ School of Pharmacy, China Medical University, Taichung 404; ${ }^{2}$ Department of Nursing, St. Mary's
Medicine Nursing and Management College, Yilan $266 ;{ }^{3}$ School of Medicine, Departments of
${ }^{4}$ Physiology, ${ }^{5}$ Biological Science and Technology, and ${ }^{6}$ Pharmacology, China Medical University,
Taichung 404; ${ }^{7}$ Department of Biotechnology, Asia University, Taichung 413, Taiwan, R.O.C.
}

Received March 29, 2012; Accepted May 18, 2012

DOI: $10.3892 /$ or.2012.1882

\begin{abstract}
Colorectal cancer (CRC) is one of the most prevalent types of cancer worldwide and a common cause of morbidity and mortality in humans. The garlic-derived organosulfur compound diallyl trisulfide (DATS) has been shown to induce apoptosis in many human cancer cell lines in vitro and also affords significant protection against cancer in animal tumor models in vivo. There is no available information to show DATS-induced apoptosis in vitro and the molecular mechanisms of apoptosis in human primary colorectal cancer cells. In this study, we investigated the cytotoxic effects in DATS in primary colorectal cancer cells. DATS inhibited the viability of primary colorectal cancer cells in a time- and dose-dependent manner. After treatment with DATS, primary colorectal cancer cells exhibited DNA condensation by DAPI stain. DATS increased reactive oxygen species (ROS) production in primary colorectal cancer cells. The mitochondria-dependent apoptotic signaling pathway was shown to be involved as determined by increase in the levels of cytochrome c, Apaf-1, AIF and caspase-3 and caspase-9 in DATS-treated primary colorectal cancer cells. The decrease in the level of $\Delta \Psi_{\mathrm{m}}$ was associated with an increase in the Bax/Bcl-2 ratio which led to activation of caspase- 9 and -3 . Based on our results, DATS induces apoptotic cell death in human primary colorectal cancer cells through a mitochondria-dependent signaling pathway.
\end{abstract}

Correspondence to: Dr Jing-Gung Chung, Department of Biological Science and Technology, China Medical University, No. 91 Hsueh-Shih Road, Taichung 404, Taiwan, R.O.C.

E-mail: jgchung@mail.cmu.edu.tw

Dr Jai-Sing Yang, Department of Pharmacology, China Medical University, No. 91 Hsueh-Shih Road, Taichung 404, Taiwan, R.O.C. E-mail: jaising@mail.cmu.edu.tw

Key words: diallyl trisulfide, apoptosis, human primary colorectal cancer cells, mitochondrial-dependent signaling pathway

\section{Introduction}

Colorectal cancer represents almost $10 \%$ of all tumors and it is the third most common form of malignancy, behind prostate and lung cancers worldwide $(1,2)$. More than $70 \%$ of colon cancers are related to diet and lifestyle and it was suggested that changes in dietary and lifestyle patterns can reduce colon cancer rates (3). Persons with a diet high in vegetables, cereals, fruits and seeds have a lower risk of colon cancer, and polyphenols in fruit led to reduce colon cancer risk experimentally (4). Thus, the therapy of the human colon cancer, induction of apoptosis is recognized as a very useful and promising approach.

Apoptosis is a mode of programmed cell death that is important for maintaining cell number, and deregulation of apoptosis may contribute to development of neurodegenerative disorders and cancer (5). There are two protein families regulating apoptosis; one is the Bcl-2 family which is involved in the initiation phase of apoptosis, and the other is caspase family of proteases that are responsible for the execution phase $(6,7)$. It is well-known that cytochrome $c$ release from the mitochondrial inter-membrane space represents an important checkpoint in apoptosis $(8,9)$. Thus, at this checkpoint, Bcl-2 family plays regulatory influence on this process (10).

Diallyl trisulfide (DATS) is one of the main activity compounds in garlic extract $(11,12)$ and has a broad-spectrum anti-neoplastic activity such as induction of apoptosis in many human cancer cells (13-19). DATS-induced apoptosis correlates with downregulation and hyper-phosphorylation of $\mathrm{Bcl}-2$ in human prostate cancer cells (20). It was reported that p38/ MAPK and caspase- 8 are involved in the process of DATSinduced apoptosis in human CNE2 cells and interact with each other (21). Recently, in our laboratory, we have found that DATS inhibited migration and invasion of human colon cancer colo 205 cells in vitro (22) and inhibited tumor growth in an allograft animal model (23).

DATS-induced apoptosis has been shown in many human cancer cells but the cytotoxic effects on human primary colorectal cancer cells have not yet been defined. Therefore, the aim of this study is to investigate the effect of DATS on 
the human primary colorectal cancer cells and to elucidate its mechanism.

\section{Materials and methods}

Chemicals and reagents. Diallyl trisufile (DATS) $(99 \%$ purity), 3-(4,5-Dimethylthiazol-2-yl)-2,5-diphenyltetrazolium bromide (MTT), propidium iodide (PI) and 4',6-diamidino2-phenylindole (DAPI) were purchased from Sigma-Aldrich Corp. (St. Louis, MO, USA). RPMI-1640 medium, fetal bovine serum (FBS), trypsin-EDTA, and penicillin/streptomycin were purchased from Gibco-BRL/Invitrogen Corp. (Grand Island, NY, USA). 2',7'-Dichlorodihydrofluorescein diacetate (DCFH-DA) and 3,3'-dihexyloxacarbocyanine iodide $\left(\mathrm{DiOC}_{6}\right)$ were purchased from Molecular Probes (Invitrogen, Eugene, OR, USA). Antibodies to cytochrome c, Apaf-1, caspase-9 and caspase-3, Bcl-2 and Bax were purchased from Cell Signaling (USA). All other chemicals used were of analytical grade.

Isolation of human primary colorectal cancer cells. Three colorectal carcinoma specimens from three patients were obtained from 2008 to 2009 from the Department of Surgery, China Medical University Hospital, Taichung, Taiwan after approval of the experiment by the hospital's Ethics Committee, and with written, informed consent from patients (IRB NO: DMR-96-IRB-72) (24). Each specimen was dissected into $1-\mathrm{mm}^{3}$ pieces, immersed in a 10 -fold volume of $0.25 \%$ trypsin solution (Sigma-Aldrich), maintained at $4^{\circ} \mathrm{C}$ overnight and then incubated for $1 \mathrm{~h}$ at $37^{\circ} \mathrm{C}$. Then the trypsin was added to the cells (each well) followed by with FBS, the solution containing released cells was collected by using centrifugation at $150 \mathrm{x} g$ for $5 \mathrm{~min}$. After centrifugation, cells in each tube were re-suspended with RPMI-1640 supplemented with $10 \%$ FBS, and seeded into a $10-\mathrm{cm}$ culture dish. Undigested tissue from each patient was immediately immersed in collagenase solution (500 U/ml in RPMI-1640 medium with $10 \%$ serum) (Sigma-Aldrich) in a plate and incubated at $37^{\circ} \mathrm{C}$ for $1 \mathrm{~h}$. Released cells were collected, centrifuged, re-suspended with RPMI-1640 medium supplemented with $10 \%$ FBS, and seeded into a culture flask. When primary cultures became confluent then cells were detached by trypsin $(0.25 \%)$-ethylenediaminetetraacetic acid (EDTA) $(0.02 \%)$ solution (Sigma-Aldrich), examined and counted under phase-contrast microscope, then were centrifuged and re-suspended with RPMI-1640 medium supplemented with $10 \%$ FBS and seeded into new culture flasks (25-27).

Cell viability assay. Human primary colorectal cancer cells were seeded onto 96 -well plates at $1 \times 10^{4}$ cells/well $24 \mathrm{~h}$ before treatment. The cultures were then rinsed in phenolfree RPMI-1640 medium and incubated with the DATS at the final concentrations $0,10,20$ and $40 \mu \mathrm{M}$ in RPMI-1640 culture medium for $24 \mathrm{~h}$. At the end of incubation, $20 \mu \mathrm{l}$ of MTT [3-(4,5-dimethylthiazol-2-yl)-2,5-diphenyltetrazolium bromide] $(5 \mathrm{mg} / \mathrm{ml})$ was added to each well and incubated for $4 \mathrm{~h}$ at $37^{\circ} \mathrm{C}$ then the MTT solution was removed and $200 \mu \mathrm{l}$ dimethylsulfoxide (DMSO) was added to dissolve the crystals. The absorbance of each well at $570 \mathrm{~nm}$ was measured by using a spectrophotometric plate reader (Bio-Rad Labora- tories, Tokyo, Japan) (24). All values were compared to the corresponding controls. All assays were performed with 3 replicates.

DAPI staining for apoptosis. Human primary colorectal cancer cells were plated in the 12 -well plates at the density of $2 \times 10^{5}$ cells/well for overnight then were treated with DATS $(20 \mu \mathrm{M})$ for $24 \mathrm{~h}$, and cells in each well were then fixed in $4 \%$ paraformaldehyde for $30 \mathrm{~min}$. Then cells from each treatment were added $0.1 \%$ Triton X-100 and maintained for $10 \mathrm{~min}$ and then incubated with $1 \mu \mathrm{g} / \mathrm{ml}$ of DAPI staining solution for $30 \mathrm{~min}$ in the dark. Apoptotic cells from each treatment and control were observed through fluorescence microscopy (Zeiss, Oberkochen, Germany) as previously described $(24,27)$.

Measurement of reactive oxygen species (ROS) production. ROS production from DATS-treated and -untreated cells was measured by flow cytometry following staining with $500 \mu \mathrm{l}$ of 2',7'-dichlorofluorescein diacetate (DCFH-DA) (Molecular Probes, Invitrogen). Human primary colorectal cancer cells were plated in the 12 -well plate at the density of $2 \times 10^{5}$ cells/ well for $24 \mathrm{~h}$ then were treated with or without DATS $(20 \mu \mathrm{M})$ for 0,6 and $12 \mathrm{~h}$. Then cells from each well were collected and were stained with $20 \mu \mathrm{M}$ DCFH-DA for $30 \mathrm{~min}$ at $37^{\circ} \mathrm{C}$ and the fluorescence intensity in cells was determined using the flow cytometer $(24,27)$.

Mitochondrial membrane potential assays. The levels of mitochondrial membrane potential $\left(\Delta \Psi_{\mathrm{m}}\right)$ from DATS-treated and -untreated cells was measured by flow cytometry following staining with $500 \mu \mathrm{l}$ of $\mathrm{DiOC}_{6}(1 \mu \mathrm{mol} / \mathrm{l}$, Invitrogen $)$ for $\Delta \Psi_{\mathrm{m}}$. Human primary colorectal cancer cells were plated in the 12 -well plate at the density of $2 \times 10^{5}$ cells/well for $24 \mathrm{~h}$ then were treated with or without DATS $(20 \mu \mathrm{M})$ for 0,6 and $12 \mathrm{~h}$. Then cells from each well were collected and were stained with $500 \mu \mathrm{l}$ of $\mathrm{DiOC}_{6}(1 \mu \mathrm{mol} / 1$, Invitrogen $)$ for $\Delta \Psi_{\mathrm{m}}$ for $30 \mathrm{~min}$ at $37^{\circ} \mathrm{C}$, and the fluorescence intensity in cells was determined using the flow cytometer (Becton-Dickinson) $(24,27)$.

Assays of caspase- 9 and caspase-3 activity. Human primary colorectal cancer cells at the density of $2 \times 10^{5}$ cells/well in $10-\mathrm{cm}$ culture dish were treated with $20 \mu \mathrm{M}$ DATS and incubated for 0 and $24 \mathrm{~h}$. The activities of caspase- 9 and caspase- 3 were assessed according to the manufacturer's instruction of caspase colorimetric kit (R\&D Systems Inc.). At the end of incubation, cells in each well were harvested and lysed in $50 \mu \mathrm{l}$ lysis buffer containing $2 \mathrm{mM}$ DTT for $10 \mathrm{~min}$ then centrifuged, the supernatant containing $200 \mu \mathrm{g}$ protein were incubated with caspase-9 and caspase-3 substrate (Ac-DEVD-pNA and Ac-IETD-pNA, respectively) in reaction buffer. Then all samples from DATA-treated and -untreated cells were incubated in 96-well flat bottom microplate at $37^{\circ} \mathrm{C}$ for $1 \mathrm{~h}$. The level of released pNA was measured with ELISA reader (Anthos Reader 2001, Anthos Labtec) at $405 \mathrm{~nm}$ wavelength as previously described $(28,29)$.

Western blot analysis. Human primary colorectal cancer cells at a density of $1 \times 10^{7}$ cells in $75 \mathrm{~T}$ flasks were incubated with $20 \mu \mathrm{M}$ DATS for 0 and $24 \mathrm{~h}$ for examining the protein levels 
A

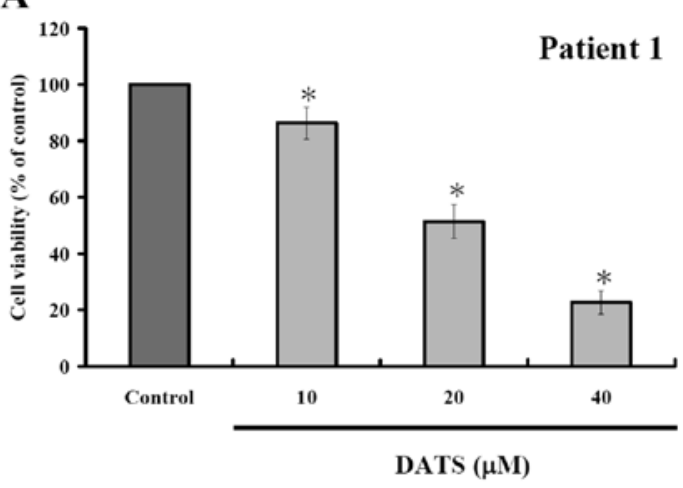

B

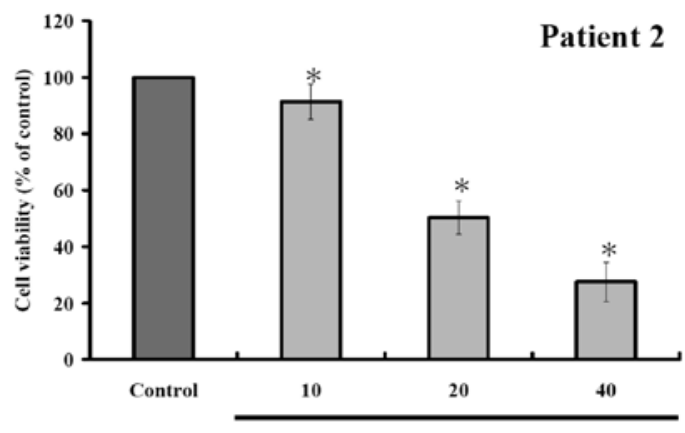

C

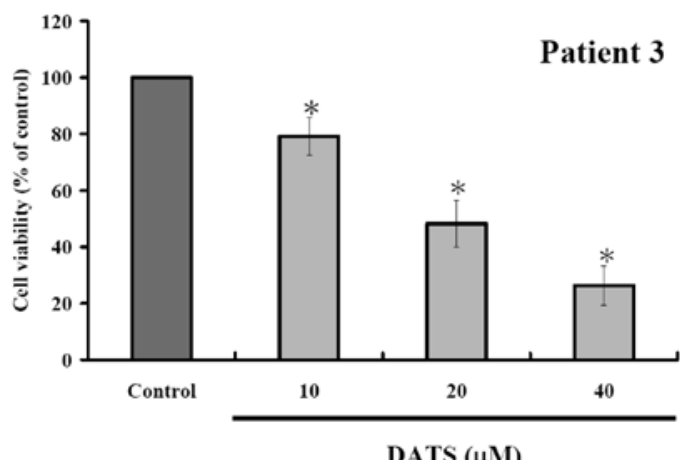

DATS $(\mu \mathrm{M})$

Figure 1. DATS decreases the percentage of viability in human primary colorectal cancer cells. Cells at a density of $2 \times 10^{5}$ cells/well in 12 -well plate were treated with $0,10,20$ and $40 \mu \mathrm{M}$ of DATS for $24 \mathrm{~h}$ then harvested for the determinations of percentage of viable cells from 3 patients (A, B and C) as described in Materials and methods. Data are presented as mean \pm SD in triplicate. ${ }^{*} \mathrm{P}<0.05$, significantly different compared between DATS and DMSO-treated groups.

correlated with apoptosis. At the end of incubation, cells from each treatment were collected, and the total protein lysate was isolated, gel electrophoresis and immunoblotting were conducted as previously described $(24,26,27)$. The primary antibodies were anti-cytochrome c, anti-Apaf-1, anti-caspase-9 and anti-caspase-3, anti-Bcl-2 and anti-Bax. Immunoreactive proteins of all examined samples were visualized with the ECL chemiluminescent detection system (Perkin-Elmer Life Science, MA, USA) and BioMax Light Film (Eastman Kodak, New Heaven, CT, USA) according to the manufacturer's instructions.

Statistical analyses. Data are presented as the mean \pm SD for the indicated number of separate experiment. Statistical

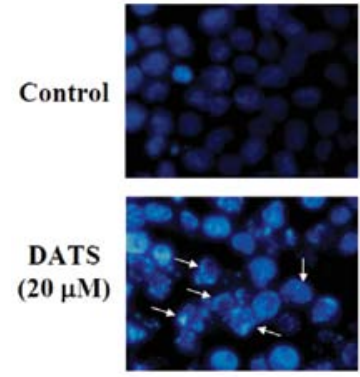

Patient 1
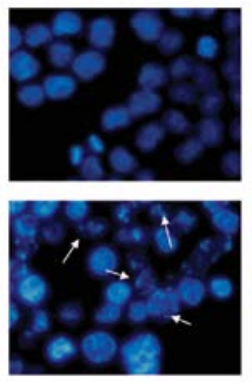

Patient 2
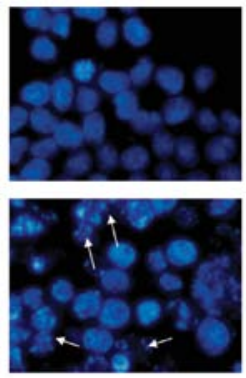

Patient 3
Figure 2. DATS induces apoptosis human primary colorectal cancer cells. Cells at the density of $2 \times 10^{5}$ cells/well in 12 -well plates were maintained $24 \mathrm{~h}$ then were incubated with 0 and $20 \mu \mathrm{M}$ of DATS for $24 \mathrm{~h}$, then isolated for the examination of apoptosis using DAPI staining and photographed under fluorescence microscopy.

analyses of data were performed by Student's t-test, and $\mathrm{P}<0.05$ was considered significant.

\section{Results}

DATS decreases the percentage of viability in human primary colorectal cancer cells. To measure DATS-mediated effects on human primary colorectal cancer cells, the cells after incubated with 10,20 and $40 \mu \mathrm{M}$ DATS for $24 \mathrm{~h}$ were harvested and the percentage of viable cells were measured by MTT assay. Results are shown in Fig. 1, indicating that increase of DATS concentration led to decreased percentage of viable cells. As expected, 24-h incubation showed apparent stronger dose-dependent effects of DATS.

DATS induces apoptosis of human primary colorectal cancer cells. To investigate the effect of DATS on nuclear alterations, cells were stained with DAPI and results are shown in Fig. 2, demonstrating that the cells underwent remarkable nuclear changes upon treatment. In the control (untreated) cells, the nuclei were intact, round, and uniformly stained. However, after exposure to DATS, the cells manifested nuclear shrinkage/condensation and nuclear fragmentation. At $20 \mu \mathrm{M}$ of DATS, a number of cells exhibited nuclear shrinkage and chromatin condensation but these aberrant nuclear alterations were not seen in the control cells. These observations showed that DATS-induced apoptosis occurred in primary colorectal cancer cells.

DATS induces reactive oxygen species (ROS) production and decreases the level of mitochondrial membrane potential $\left(\Delta \Psi_{m}\right)$ in human primary colorectal cancer cells. To investigate whether or not DATS-induced apoptosis is via the production of ROS, we measured the intracellular level of ROS during treatment with DATS by DCFH-DA and using a flow cytometer and results are shown in Fig. 3A. Results indicate that DATS induced ROS production in a time-dependent manner. The oxidation of DCF was dependent upon DATS treatment time (Fig. 3A). To investigate whether or not DATS-induced apoptosis is through decreasing the levels of mitochondrial membrane potential, cells were collected and stained with $\mathrm{DiOC}_{6}$ and results are shown in Fig. 3B, indicating that DATS 
A

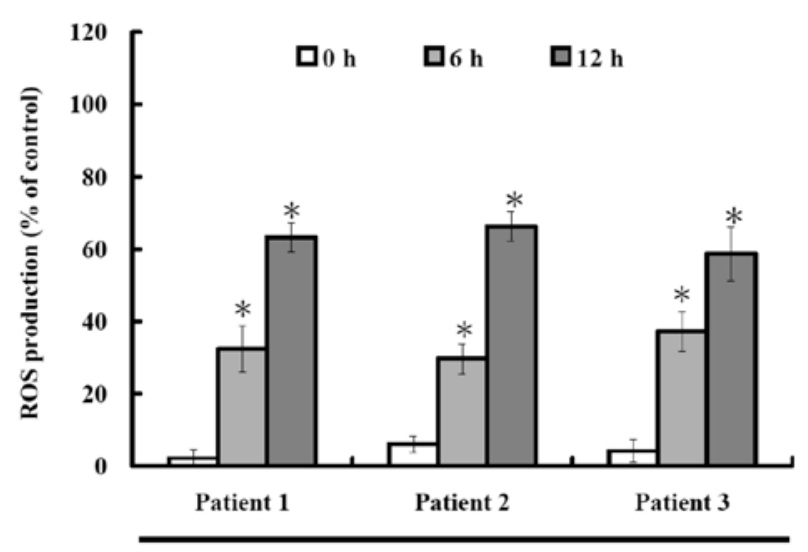

DATS $(20 \mu \mathrm{M})$

\section{B}

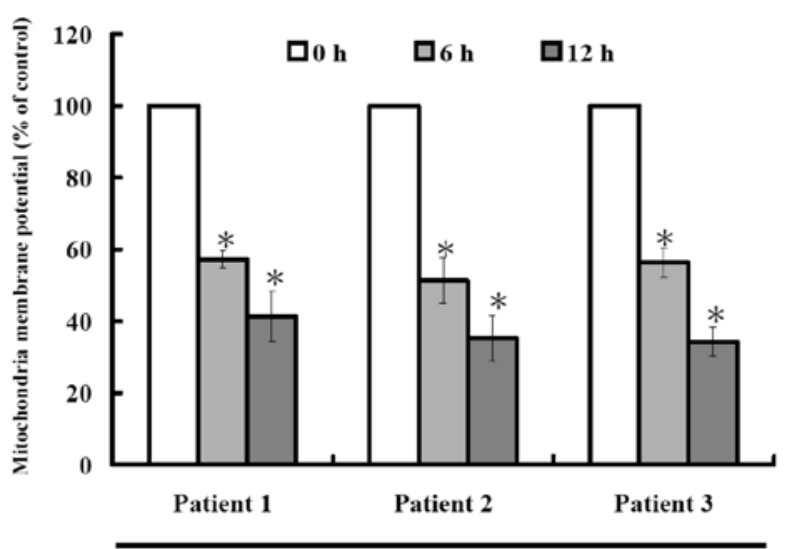

DATS $(20 \mu \mathrm{M})$

Figure 3. DATS induces reactive oxygen species (ROS) production and decreases the level of mitochondrial membrane potential $\left(\Delta \Psi_{\mathrm{m}}\right)$ in human primary colorectal cancer. Cells incubated in 12-well plates for $24 \mathrm{~h}$ were treated with or without $20 \mu \mathrm{M}$ of DATS for 0,6 and $12 \mathrm{~h}$. The cells were harvested and washed with PBS twice, re-suspended in $500 \mu \mathrm{l}$ of 2,7-dichlorodihydrofluorescein diacetate (DCFH-DA) $(10 \mu \mathrm{M})$ for ROS (A) and 3,3'-dihexyloxacarbocyanine iodide $\left(\mathrm{DiOC}_{6}\right)(1 \mu \mathrm{mol} / \mathrm{l})$ for $\Delta \Psi_{\mathrm{m}}$ (B). Cells then were incubated at $37^{\circ} \mathrm{C}$ for $30 \mathrm{~min}$ and were analyzed by flow cytometry as detailed in Materials and methods.

decreased the levels of $\Delta \Psi_{\mathrm{m}}$ in human primary colorectal cancer cells and these effects are time-dependent.

DATS affects caspase-9 and -3 activities in human primary colorectal cancer cells. To investigate whether or not DATSinduced apoptosis is via the activation of caspases, the cells after treatment with DATS were harvested and caspase- 9 and -3 activities were measured and results are shown in Fig. 4. Results indicated that DATS promoted the activation of caspase- 9 and caspase-3 in the examined cancer cells. Based on this observation, DATS induced apoptosis was via activation of caspase- 9 and caspase-3.

DATS affects apoptosis-associated proteins in human primary colorectal cancer cells. For further examining the effects of

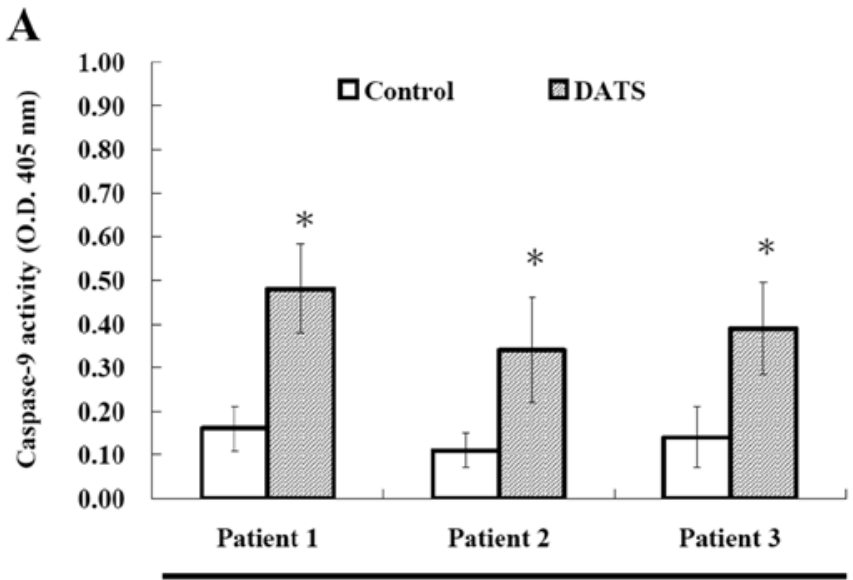

DATS $(20 \mu \mathrm{M})$

B

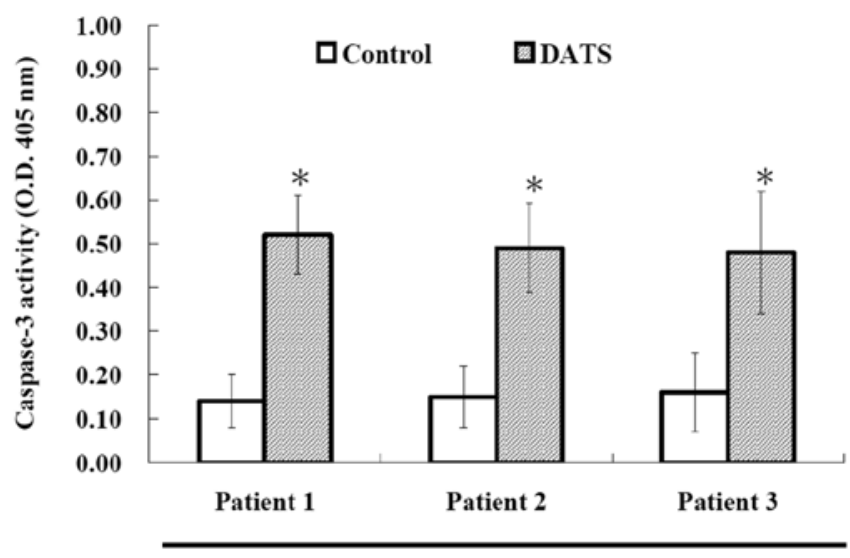

DATS $(20 \mu \mathrm{M})$

Figure 4. DATS affect caspase-9 and caspase-3 activities in human primary colorectal cancer cells. Cells $\left(2 \times 10^{5}\right.$ cells/well $)$ cultured in 12 -well plates were treated with or without $20 \mu \mathrm{M}$ DATS for 0 and $24 \mathrm{~h}$, then cells were harvested and analyzed for caspase-9 (A) and -3 (B) activities by flow cytometric analysis as described in Materials and methods. Columns, mean $(n=3)$; bars, SD. $\mathrm{P}<0.05$ significantly different compared with control.

DATS-induced apoptosis in the human primary colorectal cancer cells through apoptosis-associated protein levels, the cells after exposure to $20 \mu \mathrm{M}$ DATS for $24 \mathrm{~h}$ were harvested for western blotting and result are shown in Fig. 5. DATS increased the protein levels of cytochrome c, caspase-9 and caspase-3, showing that DATS promoted the release of cytochrome $\mathrm{c}$ from mitochondria, and then led to the activation of caspase- 9 and caspase- 3 . Furthermore, DATS promoted the pro-apoptotic protein Bax and inhibited the anti-apoptotic protein, leading to apoptosis in the three examined human colorectal cancer cell types.

\section{Discussion}

Numerous studies have shown that DATS induces cytotoxic effects in many human cancer cells through cell cycle arrest and induction of apoptosis. However, there is no information to show DATS induced apoptosis in human primary colorectal 


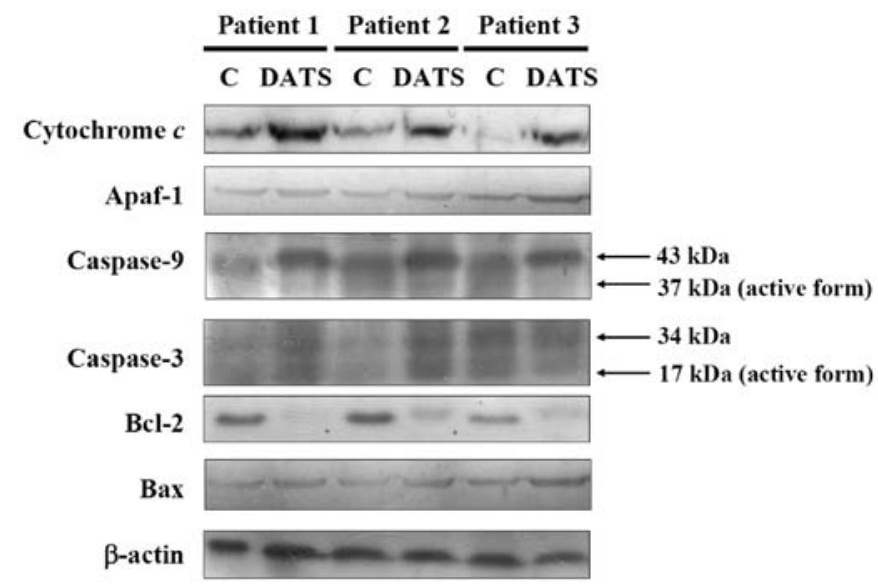

Figure 5. DATS affects apoptosis-associated proteins in human primary colorectal cancer cells. Cells ( $1 \times 10^{6} /$ well) seeded into 6-well plates were treated with $20 \mu \mathrm{M}$ of DATS then incubated for 0 and $24 \mathrm{~h}$ and harvested for western blotting to examine the protein levels of cytochrome c, Apaf-1, caspase- 9 and -3, Bcl-2 and Bax as described in Materials and methods.<smiles>C[AsH3]</smiles>

Fresh colon cancer cells from Chinese patients

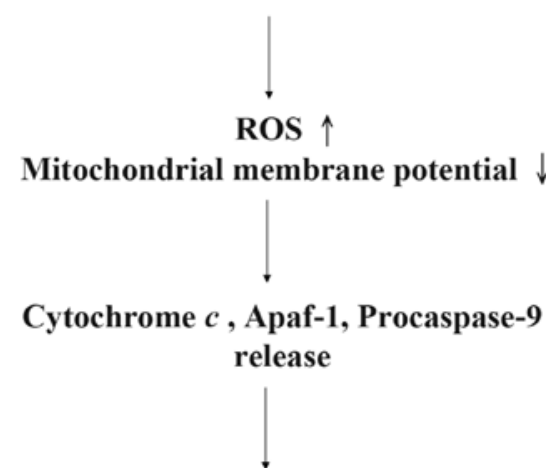<smiles>[CH]C</smiles>

Caspase- 3 activation

Cell apoptosis

Figure 6. The possible signaling pathway for DATS-induced apoptosis in human primary colorectal cancer cells.

cancer cells. Thus, the major objective of the present study was to test anticancer responses to DATS on human primary colorectal cancer cells. DATS is a well documented highly promising cancer-chemopreventive constituent of processed garlic. Recently it was reported that DATS treatment suppresses STAT3 phosphorylation in prostate cancer cells in culture and in vivo, but activation of this oncogenic transcription factor is largely dispensable for cellular responses to DATS (30).

The present study revealed that DATS treatment decreased the percentage of viable cells (Fig. 1), induced apoptosis based on DAPI staining (Fig. 2), promoted the ROS generation and decrease the levels of $\Delta \Psi_{\mathrm{m}}$ (Fig. 3) and promoted the activities of caspase-9 and -3 (Fig. 4) that were analyzed by flow cytometric assay. To clarify the underlying mechanism for DATS-induced apoptosis, we used western blotting to confirm that DATS promoted the release of cytochrome c from mitochondria and promoted the activation of caspase- 9 and -3 , further, DATS increased the pro-apoptotic protein Bax and inhibited the anti-apoptotic protein Bcl-2 leading to apoptosis (Fig. 5).

Fig. 3 indicates that DATS induced ROS generation in the 3 isolated cancer cell types and these effects are time-dependent. This is in agreement with other recent reports indicating that DATS can be reduced in cancer cells to hydroperthiol that leads to $\mathrm{H}_{2} \mathrm{O}_{2}$ generation, thereby influencing transmission of signals regulating cell proliferation and apoptosis (31). Other reports also show that the cytotoxicity caused by DATS is mediated by the generation of ROS and subsequent activation of the ASK1-JNK-Bim signal transduction pathway in human breast carcinoma MDA-MB-231 cells (32). Reports also exist showing that in vivo healthy mice injected intraperitoneally with allyl sulfides for ten days. The experiment revealed that DATS as well as DADS diminished lipid peroxidation and ROS level in normal mouse liver (31). Thus, it is possible that DATS-induced elevation of the intracellular level of ROS is due to disruption of mitochondrial electron transport chain activity, as Fig. 3 clearly demonstrates that DATS decreased the levels of $\Delta \Psi_{\mathrm{m}}$. This needs to be determined in future studies. It is well known that the ratio of $\mathrm{Bax} / \mathrm{Bcl}-2$ is involved at the level of $\Delta \Psi_{\mathrm{m}}$ in mitochondria (10). Our results from western blotting clearly showed that DATS increased the pro-apoptotic protein Bax and decreased anti-apoptotic protein Bcl-2 (Fig. 5). Thus, DATS affects the levels of $\Delta \Psi_{\mathrm{m}}$ in mitochondria via the changes in the ratio of Bax/Bcl-2. DATS has also clearly been demonstrated to promote caspase-3 activation (31). Our data showed that DATS promoted the activities of caspase- 9 and caspase-3 (Fig. 4), and also confirmed by western blotting (Fig. 5). It is well documented that apoptosis can be divided into caspase-dependent and caspase-independent pathways (33), based on our results we suggest that DATS induces apoptosis through the caspase-dependent pathway (Fig. 6).

In summary, the present study shows the cytotoxic effects of DATS via ROS generation, dysfunction of mitochondria (decreased the levels of $\Delta \Psi_{\mathrm{m}}$ in mitochondria) due to the increase in the ratio of $\mathrm{Bax} / \mathrm{Bcl}-2$, promoting the activation of caspase- 9 and -3 leading to apoptosis in human primary colorectal cancer cells.

\section{Acknowledgements}

This work was supported by the grant NSC 95-2320-B-039030-MY2 from National Science Council, Republic of China (Taiwan) and by the grant CMU97-127 from China Medical University, Taichung, Taiwan, R.O.C.

\section{References}

1. Jaramillo S, Lopez S, Varela LM, et al: The flavonol isorhamnetin exhibits cytotoxic effects on human colon cancer cells. J Agric Food Chem: Oct 5, 2010 (Epub ahead of print). 
2. Nautiyal J, Banerjee S, Kanwar SS, et al: Curcumin enhances dasatinib-induced inhibition of growth and transformation of colon cancer cells. Int J Cancer 128: 951-961, 2011.

3. van Duijnhoven FJ, Bueno-De-Mesquita HB, Ferrari P, et al: Fruit, vegetables, and colorectal cancer risk: the European Prospective Investigation into Cancer and Nutrition. Am J Clin Nutr 89: 1441-1452, 2009.

4. Davis CD and Milner JA: Gastrointestinal microflora, food components and colon cancer prevention. J Nutr Biochem 20: 743-752, 2009.

5. Fadeel B and Orrenius S: Apoptosis: a basic biological phenomenon with wide-ranging implications in human disease. J Intern Med 258: 479-517, 2005.

6. Adams JM and Cory S: Bcl-2-regulated apoptosis: mechanism and therapeutic potential. Curr Opin Immunol 19: 488-496, 2007.

7. Maiuri MC, Zalckvar E, Kimchi A and Kroemer G: Self-eating and self-killing: crosstalk between autophagy and apoptosis. Nat Rev Mol Cell Biol 8: 741-752, 2007.

8. Huttemann M, Pecina P, Rainbolt M, et al: The multiple functions of cytochrome $\mathrm{c}$ and their regulation in life and death decisions of the mammalian cell: from respiration to apoptosis. Mitochondrion 11: 369-381, 2011.

9. Kao ST, Yeh CC, Hsieh CC, et al: The Chinese medicine $\mathrm{Bu}$-Zhong-Yi-Qi-Tang inhibited proliferation of hepatoma cell lines by inducing apoptosis via G0/G1 arrest. Life Sci 69: 1485-1496, 2001.

10. Martinou JC and Youle RJ: Mitochondria in apoptosis: Bcl-2 family members and mitochondrial dynamics. Dev Cell 21 : 92-101, 2011

11. Antony ML and Singh SV: Molecular mechanisms and targets of cancer chemoprevention by garlic-derived bioactive compound diallyl trisulfide. Indian J Exp Biol 49: 805-816, 2011.

12. Seki T, Hosono T, Hosono-Fukao T, et al: Anticancer effects of diallyl trisulfide derived from garlic. Asia Pac J Clin Nutr 17 (Suppl 1): 249-252, 2008

13. Li N, Guo R, Li W, et al: A proteomic investigation into a human gastric cancer cell line BGC823 treated with diallyl trisulfide. Carcinogenesis 27: 1222-1231, 2006.

14. Sakamoto K, Lawson LD and Milner JA: Allyl sulfides from garlic suppress the in vitro proliferation of human A549 lung tumor cells. Nutr Cancer 29: 152-156, 1997.

15. Hosono T, Fukao T, Ogihara J, et al: Diallyl trisulfide suppresses the proliferation and induces apoptosis of human colon cancer cells through oxidative modification of beta-tubulin. J Biol Chem 280: 41487-41493, 2005.

16. Pinto JT and Rivlin RS: Antiproliferative effects of allium derivatives from garlic. J Nutr 131: S1058-S1060, 2001.

17. Chun HS, Kim HJ and Choi EH: Modulation of cytochrome P4501-mediated bioactivation of benzo[a]pyrene by volatile allyl sulfides in human hepatoma cells. Biosci Biotechnol Biochem 65: 2205-2212, 2001.

18. Antosiewicz J, Herman-Antosiewicz A, Marynowski SW and Singh SV: c-Jun NH(2)-terminal kinase signaling axis regulates diallyl trisulfide-induced generation of reactive oxygen species and cell cycle arrest in human prostate cancer cells. Cancer Res 66: 5379-5386, 2006.

19. Xiao D, Zeng Y, Hahm ER, Kim YA, Ramalingam S and Singh SV: Diallyl trisulfide selectively causes Bax- and Bak-mediated apoptosis in human lung cancer cells. Environ Mol Mutagen 50: 201-212, 2009.
20. Xiao D, Choi S, Johnson DE, et al: Diallyl trisulfide-induced apoptosis in human prostate cancer cells involves c-Jun $\mathrm{N}$-terminal kinase and extracellular-signal regulated kinasemediated phosphorylation of Bcl-2. Oncogene 23: 5594-5606, 2004.

21. Ji C, Ren F and Xu M: Caspase-8 and p38MAPK in DATSinduced apoptosis of human CNE2 cells. Braz J Med Biol Res 43: 821-827, 2010.

22. Lai KC, Hsu SC, Kuo CL, et al: Diallyl sulfide, diallyl disulfide, and diallyl trisulfide inhibit migration and invasion in human colon cancer colo 205 cells through the inhibition of matrix metalloproteinase-2, -7, and -9 expressions. Environ Toxicol: Jun 21, 2011 (Epub ahead of print)

23. Wu PP, Liu KC, Huang WW, et al: Diallyl trisulfide (DATS) inhibits mouse colon tumor in mouse CT-26 cells allograft model in vivo. Phytomedicine 18: 672-676, 2011.

24. Lai KC, Chiu YJ, Tang YJ, et al: Houttuynia cordata Thunb extract inhibits cell growth and induces apoptosis in human primary colorectal cancer cells. Anticancer Res 30: 3549-3556, 2010.

25. Lu CC, Yang JS, Huang AC, et al: Chrysophanol induces necrosis through the production of ROS and alteration of ATP levels in J5 human liver cancer cells. Mol Nutr Food Res 54: 967-976, 2010

26. Chiang JH, Yang JS, Ma CY, et al: Danthron, an anthraquinone derivative, induces DNA damage and caspase cascades-mediated apoptosis in SNU-1 human gastric cancer cells through mitochondrial permeability transition pores and Bax-triggered pathways. Chem Res Toxicol 24: 20-29, 2011.

27. Ho YT, Lu CC, Yang JS, et al: Berberine induced apoptosis via promoting the expression of caspase- $8,-9$ and -3 , apoptosisinducing factor and endonuclease $\mathrm{G}$ in SCC-4 human tongue squamous carcinoma cancer cells. Anticancer Res 29: 4063-4070, 2009.

28. Yang JS, Hour MJ, Huang WW, Lin KL, Kuo SC and Chung JG: MJ-29 inhibits tubulin polymerization, induces mitotic arrest, and triggers apoptosis via cyclin-dependent kinase 1-mediated Bcl-2 phosphorylation in human leukemia U937 cells. J Pharmacol Exp Ther 334: 477-488, 2010.

29. Ying WZ and Sanders PW: Cytochrome c mediates apoptosis in hypertensive nephrosclerosis in Dahl/Rapp rats. Kidney Int 59: 662-672, 2001

30. Chandra-Kuntal K and Singh SV: Diallyl trisulfide inhibits activation of signal transducer and activator of transcription 3 in prostate cancer cells in culture and in vivo. Cancer Prev Res (Phila) 3: 1473-1483, 2010.

31. Iciek M, Kwiecien I, Chwatko G, Sokolowska-Jezewicz M, Kowalczyk-Pachel D and Rokita H: The effects of garlicderived sulfur compounds on cell proliferation, caspase 3 activity, thiol levels and anaerobic sulfur metabolism in human hepatoblastoma HepG2 cells. Cell Biochem Funct 30: 198-204, 2011.

32. Lee BC, Park BH, Kim SY and Lee YJ: Role of Bim in diallyl trisulfide-induced cytotoxicity in human cancer cells. J Cell Biochem 112: 118-127, 2011.

33. Xiao D and Singh SV: Diallyl trisulfide, a constituent of processed garlic, inactivates Akt to trigger mitochondrial translocation of BAD and caspase-mediated apoptosis in human prostate cancer cells. Carcinogenesis 27: 533-540, 2006. 